\title{
The role of mother tongue literacy in language learning and mathematical learning: is there a multilingual benefit for both?
}

\section{Rebecca Dahm \& Gessica De Angelis}

To cite this article: Rebecca Dahm \& Gessica De Angelis (2018) The role of mother tongue literacy in language learning and mathematical learning: is there a multilingual benefit for both?, International Journal of Multilingualism, 15:2, 194-213, DOI: 10.1080/14790718.2017.1359275

To link to this article: https://doi.org/10.1080/14790718.2017.1359275

Published online: 06 Aug 2017.

Submit your article to this journal $\sqsubset$

Џ Article views: 167

Q View related articles $\square$

View Crossmark data ¿ 


\title{
The role of mother tongue literacy in language learning and mathematical learning: is there a multilingual benefit for both?
}

\author{
Rebecca Dahm ${ }^{a}$ and Gessica De Angelis ${ }^{b}$ \\ ${ }^{a}$ ESPE Midi-Pyrénées - Université de Toulouse Jean-Jaurès CLLE-ERSS, axe DIDAPS, France; ${ }^{b}$ Centre for \\ Language and Communication Studies, Trinity College Dublin, College Green, Dublin, Ireland
}

\begin{abstract}
The present study examines the multilingual benefit in relation to language learning and mathematical learning. The objective is to assess whether speakers of three or more languages, depending on language profile and personal histories, show significant advantages in language learning and/or mathematical learning, and whether mother tongue literacy can be associated with their performance in Maths and English language tests. Participants are all multilinguals with knowledge of French as an L1 or as a non-native language. Three core groups were examined: (a) School multilinguals $(n=449)$, typically French L1 speakers with knowledge of two additional languages learned in a formal school context; (b) Multilinguals with Literacy in the home language $(n=45)$ and Multilinguals without Literacy in the home language $(n=113)$. All participants were given a Maths test, an English language test and a questionnaire. A questionnaire for parents was also used. Results suggest a positive role of mother tongue literacy in language learning as well as mathematical learning.
\end{abstract}

\section{ARTICLE HISTORY}

Received 20 January 2017

Accepted 20 July 2017

\section{KEYWORDS}

Mathematical learning; language learning; multilingualism; multilingual benefit; mother tongue literacy; socio-economic status

\section{Introduction}

The multilingual benefit is commonly understood to refer to the range of advantages multiple language speakers display in comparison to monolingual speakers when they engage in complex activities such as learning a language or completing cognitively demanding tasks. The phenomenon is also referred to as the bilingual benefit or the bi-/multilingual benefit, depending on the number of languages known to the speaker.

The underlying assumption of this notion is that the presence of multiple languages in the mind, in addition to the experience of learning and using these languages, create the optimal condition for a range of benefits to emerge for the individual. Whether someone has knowledge of two, three or five languages, can then be expected to bring about some differences in the type or amount of advantages that can be developed in life. In the present paper, the benefit is referred to as the multilingual benefit because the population examined is multilingual.

CONTACT Gessica De Angelis gessica.deangelis@tcd.ie Centre for Language and Communication Studies, Trinity College Dublin, College Green, Dublin 2, Ireland 
We examine the multilingual benefit in relation to mother tongue literacy and two different types of learning: language learning and mathematical learning. With respect to language learning, we already know that multiple language speakers are faster and more effective language learners than monolinguals (for a review, see De Angelis, 2007), particularly in the presence of literacy in the mother tongue (Swain, Lapkin, Rowen, \& Hart, 1990) and when learning occurs in additive contexts (Cenoz \& Valencia, 1994; Keshavarz \& Astaneh, 2004; Lasagabaster, 2000; Sanz, 2000). This raises the question of whether the benefits associated with having knowledge of multiple languages is restricted to language learning, or if it can be extended to other types of learning such as, for instance, mathematical learning. That is to say, do multilingual speakers with literacy in the home language $(\mathrm{HL})$ show an advantage in language learning as well as mathematical learning? This is the core question the present study seeks to address.

\section{Literature review}

The multilingual benefit has been observed in people of all ages (Adesope, Lavin, Thompson, \& Ungerleider, 2010; Bialystok, Craik, Klein, \& Viswanathan, 2004; Carlson \& Meltzoff, 2008; Gold, Johnson, \& Powell, 2013; Gollan, Salmon, Montoya, \& Galasko, 2011; Lazaruk, 2007; Mårtensson et al., 2012) suggesting that, given certain conditions, the benefit for the individual starts early in life and can be long term.

The majority of claims stem from studies carried out with bilingual speakers, but in recent years evidence of differences between bilinguals and multilinguals has also begun to emerge (Cedden \& Sağın Şimşek, 2012; Perquin et al., 2013; Poarch \& van Hell, 2012; Stavans, 2015), showing that the knowledge of multiple languages may increase and modify the type and amount of benefits individuals will enjoy throughout life. In contrast with evidence of an overall advantage, there are research studies that associate bilingualism with some disadvantages in learning. These studies suggest that the presumed benefits are more limited and circumstantial than initially thought (Folke, Ouzia, Bright, De Martino, \& Filippi, 2016; Runnqvist, Gollan, Costa, \& Ferreira, 2013). There are also scholars who openly argue against the entire existence of a bilingual advantage for individuals, dismissing it as a myth and describing it as an 'insufferable mixture of excessive claims and weak evidence' (Morton, 2014, p. 929).

While some conflicting results are an indication that generalisations from past research may have been too ambitious for our current level of understanding of the phenomenon, the positive association between language knowledge and the development of a set of advantages for the individual are far too numerous for us to dismiss in their entirety. Some conflicting results may indeed be due to methodological practices that were not sufficiently rigorous to obtain reliable and comparable findings, which are briefly discussed below.

A first problem which is often overlooked but that may begin to explain the existence of conflicting results in the literature, relates to scholars' level of attention towards the role of previously known languages already in the mind. Attention to background languages is often minimal in research, unless participants have high fluency in one or more of their languages. It is not uncommon to find empirical studies where bilingual and multilingual participants are included in the same subject pool and prior knowledge of non-native languages is minimised or completely ignored. It is just as common to find bilinguals 
labelled as multilinguals in the literature, as if the presence of non-native languages were not a concern. These inconsistencies have had the effect of introducing confusion in the field and quite possibly a subject selection bias in past research which has obscured meaningful differences between speakers who have different language profiles (De Angelis, 2017). Inconsistent results are the inevitable outcome of such loose practices.

A further explanation may be that multilinguals show some advantages over monolinguals only in a restricted number of tasks, or in the presence of a limited set of conditions and circumstances. For instance, we already know that bilinguals with literacy in the HL learn additional languages faster and more effectively than those without literacy in the HL (Swain et al., 1990) and that socio-economic status (SES) is deeply connected with school performance and learning (Miller \& Warren, 2011). Having knowledge of several languages is clearly only one of the conditions associated with advantages for learning, but other factors play an equally crucial role in triggering the benefits, as Cummins (1976, 1979) had already argued a long time ago when he proposed his Threshold Hypothesis. According to the hypothesis, there are two levels of linguistic competence. The first must be reached to avoid the disadvantages of bilingualism, and the second must be reached for the advantages associated with bilingualism to emerge. Several studies set out to verify the claim and found evidence in its support, including in relation to mathematical learning (Clarkson \& Galbraith, 1992; Ní Ríordáin \& O'Donoghue, 2009).

Additional criticism of the multilingual benefit relates to the possible existence of another type of subject selection bias in research: immigration status. Fuller-Thomson and Kuh (2014) have argued that most bilingual participants cannot be compared with monolinguals because it is the most motivated and intelligent who migrate, hence immigrants are a self-selected group to start with. While this may be true in some context, nowadays it is unlikely that one would find a large number of multilinguals without an immigrant background, or individuals who are totally monolingual. Perquin et al. (2013), for instance, worked with residents of multilingual Luxembourg where three official languages (French, German and Luxembourgish) are spoken, in addition to other languages regularly used by the immigrant community. According to official national statistics (http://www.statistiques.public.lu), 55.8\% of the population use Luxembourgish as the main language of communication, and on average 2.2 languages are used on a daily basis. Portuguese (15.7\%) and French (12.1\%) immediately follow Luxembourgish. Within this complex multilingual context the authors examined an older cohort and found clear positive links between language background and protection against cognitive decline in old age. The result did not seem to be linked to immigrant status. Future research will certainly need to deal with the issue of conflicting results more systematically, and the use of more rigorous and reliable subject selection procedures may help us improve our understanding of core differences between speaker groups. While we acknowledge that some of the results still need to be confirmed, at present we can say that the evidence in support of the existence of a multilingual benefit seems to be considerable (see Adesope et al., 2010 for a full review) and that mother tongue literacy seems to play a role in learning. The focus of the present paper is therefore to assess whether the potential benefits related to mother tongue literacy and identified for language learning can also arise in other school subjects such as mathematical learning. 


\section{The multilingual benefit in language learning and mathematical learning}

The rationale behind looking for an association between language learning and mathematical learning is that most of the benefits identified in the literature relate to a range of skills and abilities which are relevant for learning as a general cognitive activity, and are therefore relevant to both language learning and mathematical learning. Some of these include cognitive flexibility and problem-solving (Bialystok, 1999; Bialystok \& Majumder, 1998; Leikin, 2013; Ricciardelli, 1992, 1993), attention and monitoring processes (Bialystok, Craik, \& Ryan, 2006), learning strategies (Bochner, 1996; Kemp, 2007) and metacognitive awareness (Le Pichon Vorstman, De Swart, Ceginskas, \& Van Den Bergh, 2009).

With regard to language learning, we find several explanations of bilingual's presumed superiority in learning. First, bi/multilinguals are believed to develop greater metalinguistic knowledge and metalinguistic awareness in comparison to monolinguals. As a result of having acquired an additional language, they seem to have a better awareness of the forms, meanings and rules of language, which is very useful to them during the process of learning an additional language (Diaz, 1985; Eviatar \& Ibrahim, 2000; Galambos \& Goldin-Meadow, 1990; Jessner, 2006, 2008; Ransdell, Barbier, \& Niit, 2006; Ricciardelli, 1992, 1993; Yelland, Pollard, \& Mercury, 1993). Bi-/multilinguals also show increased flexibility with regard to learning strategies, and this has been observed with individuals who are learning natural languages (see De Angelis, 2007 for a review) as well as artificial languages (McLaughlin \& Nayak, 1989; Nayak, Hansen, Krueger, \& McLaughlin, 1990).

An influential paper on mother tongue literacy and bilingualism which is central to our own work is Swain et al. (1989). Focusing on bilingual education programmes in Canada, the authors evaluated the role of mother tongue literacy in the acquisition of a third language. They examined French proficiency development with a total of 380 eight grade students who had been attending an English/French bilingual programme since grade five. Some of these students were literate in the $\mathrm{HL}$ and some were not. They found that $\mathrm{HL}$ literacy has a positive effect on third language learning and that the ability to read and write in the $\mathrm{HL}$ is more important than using the mother tongue on a regular basis. They also assessed whether overall proficiency in the $\mathrm{HL}$ is more helpful when learning a third language than literacy in the $\mathrm{HL}$ and found a statistically significant difference between the two, indicating that literacy in the HL has a positive effect on language learning regardless of the proficiency level achieved in the HL. The authors also examined SES variables and found that the higher the level of literacy in the HL, the higher the SES level of the family of origin.

SES is also a factor that we took into account in our own study as SES is widely regarded as a robust predictor of poor performance in school (Adesope et al., 2010; Krashen, 2005; Miller \& Warren, 2011; Polidano, Hanel, \& Buddelmeyer, 2013; Vale et al., 2013) and is linked to high dropout rates (Rosenblum, Goldblatt, \& Moin, 2008), but the trend can still be reversed with additional targeted work (Lindholm-Leary, 2014).

A great deal of research on bilingualism and learning has been conducted within the field of psycholinguistics, where we find that the most accredited explanation for multilinguals' presumed superiority in completing cognitively demanding task is that multilinguals are used to switching their languages on a regular basis and are therefore more used to selectively attend to input and inhibit or supress non-target information 
(Adesope et al., 2010; Bialystok, 1999; Bialystok, Majumder, \& Martin, 2003; Emmorey, Luk, Pyers, \& Bialystok, 2008).

A notion associated with the frequent switching of languages is cognitive flexibility, which refers to humans' ability to switch between two or more concepts during the completion of a task (Seçer, 2016). Switching requires a great deal of attention, monitoring and control, as one language needs to be retrieved while the other needs to be suppressed or inhibited. The ability to shift between tasks is believed to reflect our ability to shift between notions - an ability that can be argued to be just as important for language learning as for mathematical learning.

While the explanation that bilinguals are more used to selectively attend to input and suppress non-target information is logical, it can only be taken to be a partial answer, at best. Mother tongue literacy plays a facilitative role in third language learning (Swain et al., 1989) and literacy development requires the use of skills and abilities that go well beyond the capacity to attend to input and inhibit or supress non-target information. For a more comprehensive explanation we need to identify the cognitive skills that can be associated with both literacy development and mathematical learning.

Research in mathematics education has been chiefly concerned with the use of language within the classroom context and in testing (Abedi \& Lord, 2001; Bunyi, 1997; Chitera, 2012) or in the usefulness of translating concepts across languages (Farrugia, 2003) to enhance student's learning. Similarly to language learning research, variables such as low SES and parental education have been confirmed as key variables associated with the poor performance of immigrant children and adolescents (Abedi \& Lord, 2001; Hattie, 2009; Roberts \& Bryant, 2011; Schnepf, 2007) within the school context.

In contrast to language acquisition and psycholinguistics research, the notion of codeswitching is mostly conceived as a strategy which can help students understand mathematical content. In some contexts the use of code-switching is also an unavoidable choice as teaching materials are primarily available in English, and this inevitably encourages the practice of teaching maths by constantly switching between English and the language of instruction.

While textbooks may influence the choice of some pedagogical strategies over others, we also know that students are deeply affected by the language that is used to teach them basic mathematical concepts. Counting and conducting simple mathematical operations is an example of where early choices may resurface in practice. Research has found that bilingual speakers tend to favour the use of the language in which mathematical concepts were first acquired, regardless of the proficiency level achieved in that language as an adult. Salillas and Wicha (2012) carried out a series of mathematical tests with bilinguals who had learned mathematical concepts only in one language. They used a variety of measures which included both electrophysiological and behavioural responses and problems that used both numbers and digits in both English and Spanish. They found evidence of brain responses of a different kind when participants were presented with problems worded in the language in which the concept had initially been learned.

The association between bilingualism and mathematical performance has also begun to appear in the literature. Leikin (2013), for instance, carried out a study in which he compared preschool monolingual and bilingual children with the objective of finding a possible association between bilingualism and pre-schoolers' creativity in mathematical and 
non-mathematical problem-solving. The author indeed found evidence that early bilingualism as well as some form of bilingualism help children develop mathematical creativity.

Similar results but with a more narrow focus on bilinguals' performance on spatial tasks can be found in McLeay (2003). The author gave 72 test items to both monolinguals and bilinguals and asked them to compare diagrams with similar and dissimilar patterns of knotted and unknotted ropes. Participants were 11 balanced English/Welsh bilinguals and 30 monolingual English L1 speakers. Findings indicated that bilinguals are better able to solve complex tasks than monolinguals.

On the whole, the literature is largely supportive of the existence of a multilingual benefit for learning. While the evidence of a link between language background and mathematical learning has been slow to appear, some discussions are already available in the literature and are beginning to show a positive association between language background and mathematical-related performance. One way to further our understanding of the role of background languages in mathematical learning is to examine multilingual behaviour with participants that can be grouped according to different language profiles and histories, as we have done in the present study.

\section{Methods}

\section{Aims and research questions}

The objective of the present study is to examine whether multilinguals, depending on their language profile and personal histories, show significant advantages in language learning and/or mathematical learning. We pay special attention to literacy in the $\mathrm{HL}$ and SES as these two variables are already known to affect students' school performance to a significant extent. Information on SES is used to isolate and compare groups of participants who share similar SES backgrounds, a step which ensures that SES does not become an intervening variable in the study. Literacy in the $\mathrm{HL}$ is used as a core parameter to distinguish multilinguals with literacy in the $\mathrm{HL}$ from those who just learned to speak the language in the home but have not developed significant literacy skills in that language. With regard to language learning, we expect multilinguals with literacy in the $\mathrm{HL}$ to perform better than those without literacy in the $\mathrm{HL}$, as the literature already suggests (Swain et al., 1989). With regard to mathematical learning, we also expect students literate in the HL to perform better than those without literacy in the HL. That is, we expect mother tongue literacy to be associated with enhanced abilities in mathematical learning.

With these objectives in mind, the following research questions were addressed:

(1) Do School Multilinguals perform similarly to Multilinguals with a $\mathrm{HL}$, regardless of the level of literacy achieved in the HL?

(2) Is literacy in the HL associated with students' performance in language learning and/or mathematical learning?

(3) When mother and father education are controlled, is literacy in the HL associated with students' performance in language learning and/or mathematical learning? 


\section{Participants}

We selected a total of 607 participants, 326 females and 281 males, with an average age of 15. Most participants were multilingual speakers attending secondary school in the Limoges area of France; about $10 \%$ of the participants were from Bordeaux or the Burgundy region. The school from Bordeaux and the school from the Burgundy region were chosen to ensure the inclusion of schools from areas with a higher overall SES. According to French national statistics (https://www.insee.fr/fr/statistiques), the national rate of poverty at $60 \%$ for 2013 in these towns was respectively of $14.6 \%$ and $11.9 \%$ (whereas it was at $15.4 \%$ in the Limousin region). All participants were all speakers of French and they were all literate in French. Those who spoke a language other than French in the home environment differed in their level of literacy in the HL. Some ( $n=45,7.4 \%)$ had good level of literacy in the HL reporting a minimum of B1 in both reading and writing; others $(n=113,18.6 \%)$ had no literacy in the HL. SES was also fully controlled and was measured using three main indicators: mother education, father education and annual income.

At the time of the data collection, participants were attending year $9\left(3^{\text {ème }}\right)$ in the French school system. Students registered in year 9 in France are required to study at least two foreign languages at school, a requirement which then made all students multilinguals. The first foreign language (English) is introduced in primary school while the second foreign language is introduced much later. The participants in this study mainly started studying English at age 8 (year 3) and then learned a second foreign language at age 14 (year 8).

Participants were divided into three core groups: (a) School Multilinguals, (b) Multilinguals with Literacy in the HL, (c) Multilinguals without Literacy in the HL.

\section{School multilinguals $(\mathrm{n}=449)$}

These are French L1 speakers with knowledge of two additional languages learned in a formal school context. Proficiency in the two additional languages does not exceed the B1 level. In the literature we would commonly find these learners defined as native peers.

\section{Multilinguals with Literacy in the HL $(\mathrm{n}=45)$}

These are speakers of a language other than French in the home environment in which they have achieved a minimum of B1 in reading and writing, therefore, a good level of literacy overall. These participants are also familiar with other languages including French (language of instruction) and two additional languages (as per school curriculum). Even though some schools in the area offer heritage language programmes (mainly in Turkish and Arabic), very few students attended these courses. Due to this, we assume students learned to read and write in the $\mathrm{HL}$ as a result of parental efforts. The reported $\mathrm{L} 1 \mathrm{~s}$ and L2s can be found in Table 1.

\section{Multilinguals without Literacy in the $H L(n=113)$}

These are speakers of a language other than French in the home environment in which hardly any literacy has been achieved. Knowledge of other languages come in addition to French (language of instruction) and two foreign languages studied at school. 
Table 1. Multilinguals with literacy in the $\mathrm{HL}$ and their L1s and L2s $(n=45)$.

\begin{tabular}{lrr}
\hline & L1 & L2 \\
\hline Arabic & 7 & 3 \\
Armenian & 1 & 0 \\
Berber & 1 & 0 \\
Catalan & 0 & 1 \\
Comorian & 3 & 0 \\
Dutch & 1 & 2 \\
English & 0 & 4 \\
French & 15 & 26 \\
Italian & 0 & 1 \\
Lebanese & 1 & 0 \\
Lingala & 0 & 1 \\
Mahorais (Mayotte) & 1 & 1 \\
Maroccan & 0 & 1 \\
Portuguese & 1 & 2 \\
Romanian & 1 & 0 \\
Russian & 0 & 1 \\
Spanish & 1 & 1 \\
Turkish & 12 & 1 \\
\hline
\end{tabular}

The schools taking part in the study mainly offered English as a first foreign language, and sometimes Italian and German. However, most frequently, these languages (as well as Spanish) were chosen as a second or third foreign language. The reported L1s and L2s can be found in Table 2.

Regarding the schooling in HLs, an official initiative exists which is called Teaching of languages and cultures of origin (ELCO). The teaching of languages and cultures of origin helps to create favourable conditions for the mastery of the French language by pupils of families of foreign origin. Indeed, mastering the language of origin is often considered very important for immigrant students.

In 2012-2013, 92,461 pupils nation-wide took ELCO courses, of which 86,947 in primary and 5514 in secondary schools (vocational colleges and lycées).

In 2014-2015, 90,743 students took ELCO courses, including 85,718 in primary and 5025 in secondary schools (vocational colleges and vocational schools).

According to the statistics communicated by the CASNAV (M.-C. Charpentier, CASNAV Coordinator, personal communication, 2 June 2017), in the Limoges region there were 3 teachers of Arabic covering 12 primary schools and 2 lower secondary, 4 teachers of Turkish covering 14 primary schools and 4 lower secondary, 2 teachers of Portuguese covering 6 primary schools and 1 lower secondary.

\section{Sociolinguistic context: the Limousin region of France}

We regarded the Limousin region of France as highly suitable to answer the questions posed because of the average rate of immigrant students attending local schools and the lower than average socioeconomic wealth in the region. According to the French National Institute of Statistics and Economic Studies (Insee, 2013), the Limousin region is a rural area with a population density of 43.5 inhabitants $/ \mathrm{km}^{2}$, which is lower than the national average of $103.6 \mathrm{inh} / \mathrm{km}^{2}$. The rate of poverty at $60 \%$ is higher than in the rest of the country, with a rate of $15.4 \%$ in comparison to $14 \%$ at national level. The 
Table 2. Multilinguals without literacy in the $\mathrm{HL}$ and their $\mathrm{L} 1 \mathrm{~s}$ and $\mathrm{L} 2 \mathrm{~s}$ $(n=113)$.

\begin{tabular}{|c|c|c|}
\hline & L1 & L2 \\
\hline Albanian & 1 & 0 \\
\hline Arabic & 10 & 21 \\
\hline Bambara (Mali) & 1 & 0 \\
\hline Berber & 1 & 0 \\
\hline Breton (regional language) & 0 & 1 \\
\hline Cambodian & 2 & 2 \\
\hline Cameroon & 0 & 1 \\
\hline Catalan & 0 & 1 \\
\hline Chinese & 0 & 2 \\
\hline Corsican (regional language) & 0 & 1 \\
\hline Creole & 1 & 1 \\
\hline Croatian & 1 & 1 \\
\hline English & 0 & 4 \\
\hline French & 82 & 23 \\
\hline German & 0 & 1 \\
\hline Guinean & 2 & 0 \\
\hline Italian & 0 & 6 \\
\hline Kabyl & 0 & 1 \\
\hline Kurdish & 0 & 1 \\
\hline Laotian & 0 & 1 \\
\hline Lingala & 1 & 0 \\
\hline Mahorais & 3 & 2 \\
\hline Maroccan & 0 & 2 \\
\hline Mongolian & 1 & 0 \\
\hline Occitan (regional language) & 0 & 13 \\
\hline Peul & 0 & 1 \\
\hline Portuguese & 4 & 20 \\
\hline Siak (Indonesian) & 0 & 1 \\
\hline Soninké (Sénégal) & 0 & 1 \\
\hline Soussou (Guinea) & 1 & 0 \\
\hline Spanish & 0 & 2 \\
\hline Tamil & 1 & 0 \\
\hline Turkish & 2 & 2 \\
\hline Vietnamese & 0 & 1 \\
\hline
\end{tabular}

regional average of disadvantaged families is $68.77 \%{ }^{1}$ whereas the rate of disadvantaged families in the schools taking part in the study is $71.26 \%$. Even though the regional immigration rate is at $5.98 \%$ (the national rate is at $8.7 \%$ ), the percentage of foreign students in the participating schools is $8.35 \%$ whereas on a regional level it is $3.63 \%$. It is reasonable to think that the schools willing to participate in the research were those most confronted with immigration. However, this average is for the entire school: it does not necessarily represent those students who took part in the study.

\section{Instruments}

Students were given a Maths test, an English language test and a questionnaire. Parents were also given a questionnaire. The two questionnaires given to parents and students, and the Maths test were all modified or reduced version of questionnaires used in the PISA 2012 assessment exercise publicly available on the Organisation for Economic CoOperation and Development (OECD) website, www.oecd.org. Prior to giving out the two questionnaires, a written presentation was also given to all parents as well as a consent form which all families were asked to sign. An assent form was also signed by each student. 
Maths test. The maths tests included extracts from the French Pisa test for Maths 2012. A team of five teachers was set up under the leadership of the Regional inspector for Mathematics of Limoges (Inspecteur d'académie - inspecteur pédagogique régional de l'académie de Limoges). The team chose the relevant items of the PISA 2012 maths test. They chose 5 exercises which included a total all 18 questions that would be feasible to complete in a 50 minutes session. The exercises were then presented in order of complexity, starting from the easiest and ending with the most complex. Students had to fill in an answer sheet and each maths teacher was given a completed answer sheet for correction. The answer sheet ensured comparable marking practices were used across schools.

English test. The English language test included extracts from the A2/B1 Cambridge tests for English Reading. We used the A2 Key English Test for Schools Reading and Writing, A2 test $n^{\circ}$ 500/2416/4 ( ) UCLES 2014 Cambridge English Entry Level Certificate in ESOL International (Entry 2). The B1 level was from the B1 University of Cambridge ESOL Examinations, Preliminary English Test. Paper 1 Reading and Writing. Sample Paper 1. B1 test n 100/2031/7 @ UCLES 2004. Entry Level Certificate in English (ESOL) - Entry 3.

A team of three teachers under the leadership of the Regional inspector for English of Limoges (Inspecteur d'académie - inspecteur pédagogique régional de l'académie de Limoges) examined the A2 and B1 Cambridge tests. Seven exercises were chosen, four at the $A 2$ level and three at the B1 level. The final test included a total of 30 questions, 15 for each level. The team selected these 30 questions at two different levels as they were deemed to be answerable in a 50 minutes session. Each teacher was then given a completed answer sheet for correction. The answer sheet ensured comparable marking practices were used across schools.

Parents' questionnaire. The questionnaire given to all parents was a slightly modified version of the international option questionnaire used in the 2012 PISA assessment exercise (OECD), publicly available at www.oecd.org. The version was modified to fit the profile of parents and students living in France. The questionnaire was first modified in the English version, then translated into French.

Students' questionnaire. The primary purpose of the students' questionnaire was to obtain information about their language background and patterns of daily use of languages within the family context, with friends and at school. Students were first asked to indicate which language they usually spoke at home with their family and with their friends and to confirm which were the languages learned at school. They also indicated the age of first exposure for each of these languages. They then proceeded to self-assess their level of proficiency in each language in the following skills: listening, reading, spoken interaction, spoken production and writing. In order to do this, they were asked to use the Common European Framework of Reference (CEFR) self-assessment grid as their primary guideline. Students had previously engaged in a self-assessment activity with their English teacher to ensure they would already be familiar with the tool. The same grid was also added to the questionnaire to ensure the self-assessment evaluation would be as accurate as possible. The students' questionnaire was first prepared in English, and then translated into French.

\section{Results}

The data were analysed using a combination of $t$-tests and ANOVAs, depending on whether the comparison involved two or three groups. 
We first compared Maths and English test scores of School Multilinguals and all Multilinguals with a $\mathrm{HL}$ other than French, regardless of level of literacy reached in the $\mathrm{HL}$ (Table 3). An independent-samples $t$-test was conducted using language background as main independent variable. The non-significance of the Levene test for the Maths test $(p=.250)$ and the English test $(p=.648)$ indicated that the assumption of homogeneity of variance was tenable, hence equal variances were assumed. In the Maths test, School Multilinguals performed significantly better $(M=45.83, S D=19.06)$ than Multilinguals with a $\mathrm{HL}(M=37.60, \mathrm{SD}=18.40), t(573)=-4.515, p<.001$. The same difference in performance was not found in the English test. Test scores for School Multilinguals $(M=$ 42.60, $\mathrm{SD}=17.48)$ and Multilinguals with a $\mathrm{HL}(M=40.05, \mathrm{SD}=19.29)$ were similar and the difference was found to be non-significant, $t(593)=-1.490, p=.137$. Taken together, these results suggest that School Multilinguals perform better than students with a $\mathrm{HL}$ other than French in the Maths test, but not in the English test.

A one-way between subjects ANOVA was then conducted to compare both Maths and English tests scores of School Multilinguals, Multilinguals with Literacy in the HL and Multilinguals without Literacy in the $\mathrm{HL}$ (Table 4). Language background was used as main independent variable. The Levene test was non-significant for the Maths test ( $p=.524)$ so the assumption of homogeneity of variance was tenable and homogeneous variances were assumed. The Levene test was found to be significant $(p=.001)$ for English test scores hence the assumption of homogeneity of variance did not seem tenable.

Math test. The one-way between subjects ANOVA with language background as a main independent variable found a significant effect at the $p<.05$ level $[\mathrm{F}(2,572]=10.46$, $p<.001]$. Post hoc comparisons using Tukey HSD test indicated that the mean score for School Multilinguals $(M=45.83, \mathrm{SD}=19.06)$ was significantly higher $(p=<.003)$ than the mean score of Multilinguals with Literacy in the $\mathrm{HL}(M=35.84, \mathrm{SD}=18.30)$ and it was also significantly higher than the mean score $(p<.001)$ of Multilinguals without literacy in the $\mathrm{HL}(M=38.38, \mathrm{SD}=18.48)$. The difference between Multilinguals with Literacy in the $\mathrm{HL}(M=35.84, \mathrm{SD}=18.30)$ and Multilinguals without Literacy in the $\mathrm{HL}(M=38.38$, $\mathrm{SD}=18.48)$ was found to be non-significant $(p=.738)$. Taken together, these results then indicate that School Multilinguals perform better in maths than Multilinguals with a $\mathrm{HL}$, regardless of whether literacy has been achieved in the $\mathrm{HL}$.

English test. The English test scores were analysed using a $t$-test and equal variances were not assumed as the Levene test was found to be significant $(p<.001)$. Multilinguals literate in the HL $(n=43)$ performed significantly better $(M=47.09, S D=24.43)$ than Multilinguals not literate in the $\mathrm{HL}(n=104)(M=37.14, \mathrm{SD}=15.95), t(57.38)=$ 2.46, $p<.017$. Multilinguals literate in the $\mathrm{HL}(n=43)$ did not perform significantly better $(M=47.09, S D=24.43)$ than School Multilinguals $(n=448) \quad(M=42.60$, $\mathrm{SD}=17.48), t(46.22)=1.178, p=.245$, while School Multilinguals $(n=448)(M=42.60$, $\mathrm{SD}=17.48$ ) perform significantly better than Multilinguals not literate in the $\mathrm{HL}$

Table 3. Descriptive statistics of Maths and English test scores by two language profiles.

\begin{tabular}{llllr}
\hline Test type & \multicolumn{1}{c}{ Language profile } & $N$ & Mean & SD \\
\hline Maths & School Multilinguals & 432 & 45.83 & 19.06 \\
& Multilinguals with a HL & 143 & 37.60 & 18.40 \\
English & School Multilinguals & 448 & 42.60 & 17.48 \\
& Multilinguals with a HL & 147 & 40.05 & 19.29 \\
\hline
\end{tabular}


Table 4. Descriptive statistics of Maths and English test scores by three language profiles.

\begin{tabular}{llrrr}
\hline Test type & \multicolumn{1}{c}{ Language profile } & $N$ & Mean & SD \\
\hline Maths & School Multilinguals & 432 & 45.83 & 19.06 \\
& Multilinguals with Literacy in the HL & 44 & 35.84 & 18.30 \\
& Multilinguals without Literacy in the HL & 99 & 38.38 & 18.48 \\
English & School Multilinguals & 448 & 42.60 & 17.48 \\
& Multilinguals with Literacy in the HL & 43 & 47.09 & 24.43 \\
& Multilinguals without Literacy in the HL & 104 & 37.14 & 15.95 \\
\hline
\end{tabular}

$(n=104)(M=37.14, \mathrm{SD}=15.95), t(165.44)=3.082, p=.002$. Taken together, these results then suggest that literacy in a HL significantly affects performance in a language test. In particular, when those with literacy and without literacy in the $\mathrm{HL}$ are compared, those with literacy in the $\mathrm{HL}$ emerge as having achieved better results in the English test. School Multilinguals also emerge as having achieved better results than multilinguals without literacy in the HL. School multilinguals and multilinguals with literacy in the HL show a similar performance.

A one-way between subjects ANOVA was also conducted to compare Maths and English test scores of School Multilinguals, Multilinguals with Literacy in the HL and Multilinguals without Literacy in the $\mathrm{HL}$ (Table 5), with Mother Education set to include Upper Secondary and University education only. This ensured that only subjects with similar SES backgrounds would be compared. Language background was then used as main independent variable. The Levene test was non-significant for the Maths test $(p=.711)$ so the assumption of homogeneity of variance was tenable and homogeneous variances were assumed. The Levene test for English was found to be significant $(p=.004)$ hence the assumption of homogeneity of variance did not seem tenable.

Math test. The one-way between subjects ANOVA found a significant effect at the $p<.05$ level of language background $[\mathrm{F}(2,463]=3.534, p<.03]$. Post hoc comparisons using Tukey HSD test indicated that the mean score for School Multilinguals $(M=46.49$, $\mathrm{SD}=18.91)$ was significantly higher $(p=.044)$ than the mean score of Multilinguals without literacy in the $\mathrm{HL}(M=40.38, \mathrm{SD}=18.81)$ but not of Multilinguals with literacy in the $\mathrm{HL}(M=40.91, \mathrm{SD}=17.89)$. The latter difference was found to be non-significant $(p=.368)$. Taken together, these results indicate that when maternal education is controlled, Multilinguals literate in the HL perform better than those without literacy in the $\mathrm{HL}$ but their result are similar to those of School Multilinguals.

English test. The English test scores were analysed using a $t$-test and equal variances were not assumed. Multilinguals with literacy in the $\mathrm{HL}(n=22)$ performed significantly better $(M=54.86, S D=25.80)$ than Multilinguals without literacy in the HL $(n=70)(M=$ $37.27, \mathrm{SD}=16.51), t(26.62)=3.011, p<.006$. Multilinguals with literacy in the $\mathrm{HL}(n=22)$

Table 5. Mother and Father Education by students' language profiles.

\begin{tabular}{|c|c|c|c|c|c|c|}
\hline & \multicolumn{2}{|c|}{ School Multilinguals } & \multicolumn{2}{|c|}{$\begin{array}{l}\text { Multilinguals with } \\
\text { Literacy in the } \mathrm{HL}\end{array}$} & \multicolumn{2}{|c|}{$\begin{array}{l}\text { Multilinguals without } \\
\text { Literacy in the } \mathrm{HL}\end{array}$} \\
\hline & Mother & Father & Mother & Father & Mother & Father \\
\hline Primary & 0 & 5 & 5 & 2 & 5 & 3 \\
\hline Lower secondary & 55 & 88 & 15 & 8 & 29 & 23 \\
\hline Upper secondary & 167 & 161 & 13 & 20 & 38 & 45 \\
\hline University & 225 & 180 & 9 & 11 & 36 & 31 \\
\hline
\end{tabular}


$(M=54.86, S D=25.80)$ also performed significantly better than School Multilinguals $(n=$ 391) $(M=42.80, \mathrm{SD}=17.58), t(22.11)=2.166, p=.041$. School Multilinguals $(n=391)$ performed significantly better $(M=42.80, S D=17.58)$ than Multilinguals not literate in the $\mathrm{HL}(n=70)(M=37.27, \mathrm{SD}=16.51), t(99.148)=-2.554, p=<.012$.

Taken together, these results indicate that when maternal education is controlled, Multilinguals with literacy in the HL perform better than all other students. School Multilinguals only perform better than students who have no literacy in the HL.

Similar patterns arise with Father Education set to Upper Secondary and University combined. A one-way between subjects ANOVA was conducted to compare Maths and English test scores of School Multilinguals, Multilinguals with Literacy in the HL and Multilinguals without Literacy in the HL (Table 5). This ensured that only subjects with similar SES would be compared, and language background was used as main independent variable. The Levene test was non-significant for the Maths test ( $p=.947)$ so the assumption of homogeneity of variance was tenable and homogeneous variances were assumed. The Levene test for English was found to be significant $(p=.004)$ hence the assumption of homogeneity of variance did not seem tenable.

Math test. The one-way between subjects ANOVA found a significant effect at the $p<.05$ level of language background $[\mathrm{F}(2,424]=9.021, p<.001]$. Post hoc comparisons using Tukey HSD test indicated that the mean score for School Multilinguals $(n=332)$ $(M=47.41, \mathrm{SD}=18.93)$ was not significantly higher $(p=.046$, rounded $p=.05)$ than the mean score of Multilinguals with literacy in the $\mathrm{HL}(M=39.03, \mathrm{SD}=19.37)$ while it was significantly higher $(p=.001)$ of the score of the mean score of Multilinguals without literacy in the $\mathrm{HL}(M=37.56, \mathrm{SD}=19.22)$. Taken together, these results indicate that when paternal education is controlled, School Multilinguals show a performance in Maths that is similar to those of Multilinguals literate in the $\mathrm{HL}$, while they seem to perform much better than those without literacy in the HL. Literacy, once again, seems to help Multilinguals with a $\mathrm{HL}$ reach native peers.

English test. The English test scores were analysed using a $t$-test and equal variances were not assumed. Multilinguals literate in the $\mathrm{HL}(n=31)$ did not perform significantly better $(M=46.94, S D=25.55)$ than Multilinguals not literate in the $\mathrm{HL}(n=70)$ $(M=37.01, \mathrm{SD}=17.37), \mathrm{t}(42.73)=1.970, p<.055$. School Multilinguals $(n=341)$ did not perform significantly better $(M=43.28, S D=17.72)$ than Multilinguals with literacy in the $\mathrm{HL}(n=31)(M=46.94, \mathrm{SD}=25.55), t(32.68)=.779, p=.441$. School Multilinguals $(n=341)$ performed significantly better $(M=43.28, S D=17.72)$ than Multilinguals non literate in the HL $(n=70)(M=37.01, \mathrm{SD}=17.35), t(100.79)=-2.743, p=<.007$.

Taken together, these results show that when paternal education is controlled, Multilinguals with literacy in the HL performed similarly to those without literacy in the HL. School Multilinguals seem to be performing better than Multilinguals without literacy in the HL.

The data with annual income information were not computed due to low numbers for Multilinguals with and without literacy in the HL (Table 6).

\section{Discussion}

The present study compared multilinguals with different language profiles with the objective to examine whether prior language background and personal history can be associated with advantages in language learning and/or mathematical learning. The three 
Table 6. Family annual income by students' language profiles.

\begin{tabular}{lccccr}
\hline & Less than & $15,000-$ & $35,000-$ & $55,000-$ & Above \\
& 15,000 & 35,0000 & 55,000 & 75,000 & 75,000 \\
\hline School Multilinguals & 44 & 135 & 83 & 46 & 32 \\
Multilinguals Literate in the HL & 13 & 11 & 3 & 1 & 1 \\
Multilinguals not Literate in the HL & 26 & 39 & 8 & 5 & 1 \\
\hline
\end{tabular}

core groups examined were School Multilinguals (native speakers of French with knowledge of two foreign languages learned at school), Multilinguals literate in the HL, Multilinguals not literate in the HL. The discussion that follows is organised by research question.

Do School Multilinguals perform similarly to Multilinguals with a home language, regardless of the level of literacy achieved in the home language?

The answer to this question is mixed. With regard to Maths, results show that School multilinguals, that is, native peers, perform better than Multilinguals who have a $\mathrm{HL}$ other than French, regardless of the level of literacy achieved in the HL. This pattern of performance confirms what a vast amount of literature already indicates, specifically that native speakers perform better than immigrant children and adolescents in Maths (Miller \& Warren, 2011).

The positive effect of having knowledge of other languages begins to surface when we examine the English test scores. School multilinguals were found to perform as well as Multilinguals with a $\mathrm{HL}$, regardless of the level of literacy achieved in the HL. This pattern was also expected, as bilingualism is typically associated with enhanced performance in language tests.

These initial results taken together suggest that language background has a facilitative effect on learning, in particular on language learning. We also know from past literature that mother tongue literacy affects language learning to a significant extent. We therefore asked an additional question, specifically focused on the role of mother tongue literacy in language and mathematical learning.

Is literacy in the home language associated with students' performance in language learning and/or mathematical learning?

The answer to this question is also mixed. When literacy in the $\mathrm{HL}$ is taken into account in the evaluation of Maths test scores, School multilinguals seem to perform better than all other students, regardless of whether literacy was achieved in the $\mathrm{HL}$ or not. This result would then indicate that mother tongue literacy does not affect mathematical learning to any meaningful extent. With regard to the English test, however, those with literacy in the $\mathrm{HL}$ seem to achieve the best results overall so the general expected pattern of bilinguals performing better than native peers is confirmed. Moreover, School Multilinguals perform better than multilinguals without literacy in the $\mathrm{HL}$ showing, once again, how literacy seems to be a key discriminant in language learning. School multilinguals and multilinguals with literacy in the $\mathrm{HL}$ also show a similar performance, which confirms how literacy in the $\mathrm{HL}$ helps learners either achieve better results or, as in this case, reach native peers. If we look at the means obtained, we actually see that Multilinguals literate in the $\mathrm{HL}$ exceeded $(M=47.09)$ the scores obtained by School Multilinguals $(M=42.60)$.

If we were to stop our analysis here, our general conclusion would be that mother tongue literacy positively affects language learning but does not seem to affect mathematical learning. We also know, however, that poor SES is a robust predictor of school 
performance, particularly in subjects such as Maths or language. To rule out the possibility that results are due to SES rather than level of literacy achieved in the HL, we then examined Maths and English test scores by selecting students from families whose parents shared a similar level of education. This led us to ask our third research question.

When mother and father education are controlled, is literacy in the home language associated with students' performance in language learning and/or mathematical learning?

Our measures of SES were Mother Education, Father Education and Annual Income. We were able to analyse the data using mother education and father education, but we could not analyse the data on annual income since numbers were too low for any meaningful analysis to be conducted.

When maternal education is controlled, the previous finding that School multilinguals perform better in Maths than multilinguals with or without literacy in the HL is no longer confirmed. When we compare students with similar SES backgrounds we find that Multilinguals who are literate in the HL perform better in Maths than those without literacy in the $\mathrm{HL}$, and similarly to School Multilinguals. In other words, results show that mother tongue literacy helps multilinguals reach native peers faster and perform similarly to them in mathematical tests. A similar result seems to emerge when we control SES through paternal education. School multilinguals, therefore native peers, show a performance that is similar to those of Multilinguals literate in the $\mathrm{HL}$, while they seem to perform much better in Maths than those without literacy in the HL. Mother tongue literacy, once again, seems to help Multilinguals with a $\mathrm{HL}$ reach the level of native peers faster and obtain comparable results in mathematical tests. Mother tongue literacy, in other words, seems to provide an overall benefit for mathematical learning.

With regard to the English test, results show that when maternal education is controlled, Multilinguals literate in the $\mathrm{HL}$ perform better than those without literacy in the $\mathrm{HL}$ and their result are similar to those of School Multilinguals. In sum, multilinguals with literacy in the $\mathrm{HL}$ perform better than those without literacy in the HL and as well as native peers, regardless of whether SES is controlled or not. With or without monitoring maternal education as a discriminant, mother tongue literacy is a robust predictor of second language development. When paternal education is controlled, Multilinguals with literacy in the HL perform as those without literacy in the HL. School Multilinguals seem to perform better than Multilinguals without literacy in the HL.

Taken together, the results indicate that mother tongue literacy plays a role in mathematical learning as well as language learning. It may be recalled that we looked at these two types of learning because many of the benefits associated with what is commonly known as the multilingual benefit is relevant to learning as a general cognitive activity. Moreover, we wanted to go beyond the current explanation that the multilingual benefit is due to bilinguals' enhanced ability to attend to input due to the frequent switching between languages. We believed this answer to be partial at best, as there is more to language than input alone. We therefore looked further into the possible role of other factors also known to affect learners' behaviour to a significant extent such as mother tongue literacy.

We acknowledge the number of variables that need to be taken into account in a study of this kind are many, and limitations are to a certain extent unavoidable. One of these, for instance, relates to assessing students' level of literacy in their mother tongues. Knowing that the immigrant families in the Limoges area would be of various origins, we were 
expecting to find a large number of different languages being spoken. A summary of these languages can be found in Tables 1 and 2. It was objectively difficult for us to formally assess students' level of literacy in all the languages reported and due to this difficulty, we opted for self-assessment, using indicators students were already familiar with. Since there was no benefit or reward associated with self-assessment, students had no reason to provide inaccurate information to us. Future research may nonetheless wish to examine mother tongue literacy in more detail in sociolinguistic contexts that are less diverse than the one we examined.

A second limitation relates to the use of the annual income variable for our analysis. Unfortunately, the rate of response to this question was about $70 \%$, and most of the families that responded reported earnings of 35,000 Euro or lower. Due to this, number was far too small for us to be able to conduct meaningful statistical analysis.

A third limitation relates to students' school histories, including possible past failures. We did not have access to this kind of information, but this is a variable that future studies might wish to consider in more detail.

\section{Conclusion}

Having knowledge of multiple languages is typically associated with a range of cognitive benefits for the individual, including the ability to learn languages faster and more effectively in comparison to monolinguals. The present study examined whether the benefits typically associated with language learning could also be argued to be associated with other types of learning, such as mathematical learning.

The study examined three core groups of multilinguals with different language profiles and personal histories: School Multilinguals (native speakers of French with knowledge of two foreign languages learned at school), Multilinguals literate in the $\mathrm{HL}$, Multilinguals not literate in the HL. Evidence of a positive association between multilingualism, language learning and mathematical learning was presented and discussed.

While mother tongue literacy was a crucial discriminant for our results, other factors such as SES also proved to be central to understanding our results. We were not however surprised to see a clear link between the multilingual benefit, language learning and mathematical learning as literacy development involves the use of several skills.

To appreciate the number of possible benefits that may arise from having knowledge of multiple languages we need to think of what children do with the language(s) they are learning. Literacy development involves learning a great deal of content as well as developing the skills necessary to deal with the newly acquired content. Children need to learn to understand the shape of letters, how they sound, how they are written and sometimes using different alphabets. Through this activity, which typically starts in preschool or within the home environment, children begin to understand that language is a system made of arbitrary symbols, and that each language has its own structure. They also learn to distinguish different sounds, developing language-specific phonemic knowledge and the ability to identify rhymes or similarities of various kinds, both in the sound and the meaning of the words they encounter. Multilingual children develop vocabulary in several languages simultaneously, while they also develop the necessary skills to speak to others 
in different languages. These skills include the strategies that allow children to identify when they should use one language over another, with whom, and in which context.

All these activities related to literacy development are quite complex for young minds who have to learn to manage two or more language systems and understand when to use them and with whom. Language problem-solving typically becomes second nature for multilingual children, even though anyone who has observed them go through language development reports the existence of a certain amount of frustration when, for instance, two words are identical in two languages, or children do not know the word they want to use in the language they are speaking. Frustrations aside, all these early language activities help the child develop early problem-solving strategies, early abilities to negotiate meaning, early understanding of interlocutor behaviour. The child also develops different communication strategies ranging from waiting to hear what language someone is using to identifying a place with one specific language, or translating words from one language to another for themselves or family members. Individual decision-making is a substantial part of personal cognitive development, and it should come to no surprise that children who go through literacy development in more than one language show an added benefit in learning.

The association between language development and mathematical learning is not new but, as we have seen, only a handful of studies so far have focused on identifying the factors that may influence the development of skills and ability useful for both mathematical and language learning. The extent to which two or more languages are interacting with one another in the development of literacy skills and how the practice of such constant interactions may ultimately affect the individual's ability to learn maths as opposed to language are yet to be determined. Clearly the constant switching between the two languages represents one face of the coin. Learning to read and write in another language places additional demands on the learner who is building knowledge by developing and refining cognitive skills and abilities suitable for the learning task at hand. Mother tongue literacy can therefore be viewed as an added value, which seems to place multilingual learners at a great advantage when learning an additional language but also when learning other school subjects like maths. The present study has identified that the positive role of mother tongue literacy is not restricted to language learning, but can be extended to mathematical learning. Future research will have to identify what other factors may affect the development of the cognitive skills needed for both mathematical development and language development, as well as their specific role in shaping multilingual behaviour in children. Our results suggest that research on the association between mathematical learning and literacy development is a line of enquiry worth pursuing further due to its relevance for the educational policies of an increasingly multilingual world.

\section{Acknowledgements}

The authors would like to thank the inspectors, researchers, teachers and students of the Académies of Limoges, Bordeaux and Dijon (France) who took so willingly part in this research.

\section{Disclosure statement}

No potential conflict of interest was reported by the authors. 


\section{Note}

1. As the study was supported by M. JOHANN, Recteur de l'Académie de Limoges in 2014, the regional statistics and the statistics of the schools were exceptionally released by the regional educational services, under the authority of M. Ravaille, Secretary general of the Rectorat de Limoges. They were aggregated so as to respect anonymity.

\section{References}

Abedi, J., \& Lord, C. (2001). The language factor in mathematics tests. Applied Measurement in Education, 14, 219-234. doi:10.1207/S15324818AME1403_2

Adesope, O. O., Lavin, T., Thompson, T., \& Ungerleider, C. (2010). A systematic review and meta-analysis of the cognitive correlates of bilingualism. Review of Educational Research, 80, 207-245.

Bialystok, E. (1999). Cognitive complexity and attentional control in the bilingual mind. Child Development, 70, 636-644.

Bialystok, E, Craik, F. I. M., Klein, R., \& Viswanathan, M. (2004). Bilingualism, aging, and cognitive control: Evidence from the Simon task. Psychology and Aging, 19, 290-303.

Bialystok, E., Craik, F. L. M., \& Ryan, J. (2006). Executive control in a modified anti-saccade task: Effects of aging and bilingualism. Journal of Experimental Psychology: Learning, Memory and Cognition, 32, 1341-1354.

Bialystok, E., \& Majumder, S. (1998). The relationship between bilingualism and the development of cognitive processes in problem solving. Applied Psycholinguistics, 19, 69-85.

Bialystok, E., Majumder, S., \& Martin, M. M. (2003). Developing phonological awareness: Is there a bilingual advantage? Applied Psycholinguistics, 24, 27-44.

Bochner, S. (1996). The learning strategies of bilingual versus monolingual students. British Journal of Educational Psychology, 66, 83-93.

Bunyi, G. (1997). Multilingualism and discourse in primary school mathematics in Kenya. Language, Culture and Curriculum, 10(1), 52-65. doi:10.1080/07908319709525240

Carlson, S. M., \& Meltzoff, A. N. (2008). Bilingual experience and executive functioning in young children. Developmental Science, 11(2), 282-298.

Cedden, G., \& Sağın Şimşek, C. (2012). The impact of a third language on executive control processes. International Journal of Bilingualism, 18(6), 558-569.

Cenoz, J., \& Valencia, J. F. (1994). Additive trilingualism: Evidence from the Basque country. Applied Psycholinguistics, 15, 195-207.

Chitera, N. (2012). Language-in-Education policies in conflict: Lessons from Malawian mathematics teacher training classrooms. African Journal of Research in Mathematics, Science and Technology Education, 16(1), 58-68.

Clarkson, P. C., \& Galbraith, P. (1992). Bilingualism and mathematics learning - another perspective. Journal for Research in Mathematics Education, 23, 34-44.

Cummins, J. (1976). The influence of bilingualism on cognitive growth: A synthesis of research findings and explanatory hypotheses. Working Papers on Bilingualism, 9, 1-43.

Cummins, J. (1979). Linguistic interdependence and educational development of bilingual children. Review of Educational Research, 49, 222-251.

De Angelis, G. (2007). Third or additional language acquisition. Clevedon: Multilingual Matters.

De Angelis, G. (2017). Dealing with multilingualism in quantitative research. In H. Rose \& J. McKinley (Eds.), Doing research in applied linguistics (pp. 91-100). Abingdon: Routledge.

Diaz, R. M. (1985). The intellectual power of bilingualism. Quarterly Newsletter of the Laboratory of Comparative Human Cognition, 7, 16-22.

Emmorey, K., Luk, G., Pyers J. E., \& Bialystok, E. (2008). The source of enhanced cognitive control in bilinguals. Psychological Science, 79, 1201-1206.

Eviatar, Z., \& Ibrahim, R. (2000). Bilingual is as bilingual does: Metalinguistic abilities of Arabic-speaking children. Applied Psycholinguistics, 21, 451-471.

Farrugia, M. T. (2003). From one language to another: a semiotic interpretation of the translation of mathematical words. Research in Mathematics Education, 5(1), 31-44. doi: 10.1080/14794800008520113 
Folke, T., Ouzia, J., Bright, P., De Martino, B., \& Filippi, R. (2016). A bilingual disadvantage in metacognitive processing. Cognition, 150, 119-132. doi:10.1016/j.cognition.2016.02.008

Fuller-Thomson, E., \& Kuh, D. (2014). The healthy migrant effect may confound the link between bilingualism and delayed onset of Alzheimer's disease. Cortex, 52(0), 128-130.

Galambos, S. J., \& Goldin-Meadow, S. (1990). The effects of learning two languages on levels of metalinguistic awareness. Cognition, 34, 1-56.

Gold, B. T., Johnson, N. F., \& Powell, D. K. (2013). Lifelong bilingualism contributes to cognitive reserve against white matter integrity declines in aging. Neuropsychologia, 51(13), 2841-2846.

Gollan, T. H., Salmon, D. P., Montoya, R. I., \& Galasko, D. R. (2011). Degree of bilingualism predicts age of diagnosis of Alzheimer's disease in low-education but not in highly educated Hispanics. Neuropsychologia, 49(14), 3826-3830.

Hattie, J. A. C. (2009). Visible learning: A synthesis of over 800 meta-analyses relating to achievement. New York: Routledge.

Insee, R. P. (2013). Exploitation principale en géographie au 01/01/2015. Retrieved from https://www. insee.fr/fr/statistiques/1405599?geo=REG-74+FRANCE-1+ARR-711+ARR-332

Jessner, U. (2006). Linguistic awareness in multilinguals: English as a third language. Edinburgh: Edinburgh University Press.

Jessner, U. (2008). A DST-model of multilingualism and the role of metalinguistic awareness. Modern Language Journal, 92(2), 270-283.

Kemp, C. (2007). Strategic processing in grammar learning: Do multilinguals use more strategies? International Journal of Bilingualism, 4, 241-261.

Keshavarz, M. H., \& Astaneh, H. (2004). The impact of bilinguality on the learning of English vocabulary as a foreign language (L3). International Journal of Bilingual Education and Bilingualism, 7(4), 295-302.

Krashen, S. (2005). The hard work hypothesis: Is doing your homework enough to overcome the effects of poverty? Multicultural Education, 12(4), 16-19.

Lasagabaster, D. (2000). Language learning and the development of metalinguistic awareness. Rassegna Italiana di Linguistica Applicata, 1/00, 103-116.

Lazaruk, W. (2007). Linguistic, academic and cognitive benefits of French immersion. The Canadian Modern Language Review, 63(5), 605-628.

Le Pichon Vorstman, E., De Swart, H., Ceginskas, V., \& Van Den Bergh, H. (2009). Language learning experience in school context and metacognitive awareness of multilingual children. International Journal of Multilingualism, 6(3), 258-280.

Leikin, M. (2013). The effect of bilingualism on creativity: Developmental and educational perspectives. International Journal of Bilingualism, 17(4), 431-447. doi:10.1177/1367006912438300

Lindholm-Leary, K. (2014). Bilingual and biliteracy skills in young Spanish-speaking low-SES children: Impact of instructional language and primary language proficiency. International Journal of Bilingual Education and Bilingualism, 17(2), 144-159.

Mårtensson, J., Eriksson, J., Bodammer, N. C., Lindgren, M., Johansson, M., Nyberg, L., \& Lövdén, M. (2012). Growth of language-related brain areas after foreign language learning. Neurolmage, 63 (1), 240-244. doi:10.1016/j.neuroimage.2012.06.043

McLaughlin, B., \& Nayak, N. (1989). Processing a new language: Does knowing other languages make a difference? In W. H. Dechert \& M. Raupach (Eds.), Interlingual processes (pp. 5-16). Tübingen: Gunter Narr Verlag.

McLeay, H. (2003). The relationship between bilingualism and the performance of spatial tasks. International Journal of Bilingual Education and Bilingualism, 6, 423-438.

Miller, D. C., \& Warren, L. K. (2011). Comparative indicators of education in the United States and other G-8 countries: 2011 (NCES 2012-007). Washington, DC: U.S. Department of Education, National Center for Education Statistics, U.S. Government Printing Office.

Morton, J. B. (2014). Sunny review casts a foreboding shadow over status quo bilingual advantage research. Applied Psycholinguistics, 35(5), 929-931. doi:10.1017/S0142716414000277

Nayak, N., Hansen, N., Krueger, N., \& McLaughlin, B. (1990). Language-learning strategies in monolingual and multilingual adults. Language Learning, 40(2), 221-244. 
Perquin, M., Vaillant, M., Schuller, A.-M., Pastore, J., Dartigues J.-F., Lair M.-L., \& Diederich, N. (2013). Lifelong exposure to multilingualism: New evidence to support cognitive reserve hypothesis. PLOS ONE, 8(4), e62030. doi:10.1371/journal.pone.0062030

Poarch, Gregory J., \& van Hell, Janet G. (2012). Executive functions and inhibitory control in multilingual children: Evidence from second-languages learners, bilinguals and trilinguals. Journal of Experimental Child Psychology, 113, 535-551.

Polidano, C., Hanel, B., \& Buddelmeyer, H. (2013). Explaining the socio-economic status school completion gap. Education Economics, 21(3), 230-247.

Ransdell, S., Barbier, M., \& Niit, T. (2006). Metacognitions about language skill and working memory among monolingual and bilingual college students: When does multilingualism matter? International Journal of Bilingual Education and Bilingualism, 9, 728-741.

Ricciardelli, L. A. (1992). Creativity and bilingualism. Journal of Creative Behavior, 26, 242-254.

Ricciardelli, L. A. (1993). An investigation of the cognitive development of Italian-English bilinguals and Italian monolinguals from Rome. Journal of Multilingual and Multicultural Development, 14, 345-346.

Ní Ríordáin, M., \& O’Donoghue, J. (2009). The relationship between performance on mathematical word problems and language proficiency for students learning through the medium of Irish. Educational Studies in Mathematics, 71(1), 43-64.

Roberts, G., \& Bryant, D. (2011). Early mathematics achievement trajectories: English-language learner and native English-speaker estimates, using the early childhood longitudinal survey. Developmental Psychology, 47(4), 916-930. doi:10.1037/a0023865

Rosenblum, S., Goldblatt, H., \& Moin, V. (2008). The hidden dropout phenomenon among immigrant high-school students: The case of Ethiopian adolescents in Israel - a pilot study. School Psychology International, 29(1), 105-127.

Runnqvist, E., Gollan, T. H., Costa, A., \& Ferreira, V. S. (2013). A disadvantage in bilingual sentence production modulated by syntactic frequency and similarity across languages. Cognition, 129(2), 256263. doi:10.1016/j.cognition.2013.07.008

Salillas E., Wicha N. Y. (2012). Early learning shapes the memory networks for arithmetic: Evidence from brain potentials in bilinguals. Psychological Science, 23, 745-755. doi:10.1177/ 0956797612446347

Sanz, C. (2000). Bilingual education enhances third language acquisition: Evidence from Catalonia. Applied Psycholinguistics, 2, 23-44.

Schnepf, S. V. (2007). Immigrants' educational disadvantage: An examination across ten countries and three surveys. Journal of Population Economics, 20, 527-545. doi:10.1007/s00148-006-0102-y

Seçer, I. (2016). Skills of cognitive flexibility in monolingual and bilingual younger adults. The Journal of General Psychology, 143(3), 172-184. doi:10.1080/00221309.2016.1200530

Stavans, A. (2015). If you know Amharic you can read this: Emergent literacy in multilingual pre-reading children. In G. De Angelis, U. Jessner, \& M. Kresić (Eds.), Crosslinguistic influence and crosslinguistic interaction in multilingual language learning (pp. 163-186). Oxford: Bloomsbury.

Swain, M., Lapkin, S., Rowen, N., \& Hart, D. (1990). The role of mother tongue literacy in third language learning. Language, Culture and Curriculum, 3(1), 65-81.

Vale, C., Weaven, M., Davies, A., Hooley, N., Davidson, K., \& Loton, D. (2013). Growth in literacy and numeracy achievement: Evidence and explanations of a summer slowdown in low socio-economic schools. Australian Educational Researcher, 40(1), 1-25.

Yelland, G., Pollard, J., \& Mercury, A. (1993). The metalinguistic benefits of limited contact with a second language. Applied Psycholinguistics, 14, 423-444. 